\title{
PICASSO Y EL RUEDO: SOBRE SU IDEA DE PLAZA DE TOROS
}

\author{
PICASSO AND THE ARENA: HIS IDEA ABOUT \\ BULLRING
}

\author{
FÁtima HalcóN \\ Universidad de Sevilla. España \\ fhao@us.es
}

\begin{abstract}
Análisis de la visión de la plaza de toros a través de la obra de Picasso en pintura, grabado y cerámica desde sus comienzos hasta los años setenta, su preferencia por la figura elíptica o circular para representarla y la modernidad del proyecto arquitectónico de plaza de toros que firmó junto al torero Luis Miguel Dominguín y el arquitecto Antonio Bonet i Castellana. Comparación de ese novedoso proyecto del año 1964 con los proyectos de edificación y renovación de otras plazas de toros españolas y americanas.

Palabras clave: Picasso; arquitectura; plazas de toros; grabado; cerámica.
\end{abstract}

Analysis of the vision of the bullring through the work of Picasso in painting, engraving and ceramic from the beginning to the seventies, his preference for the elliptical or circular figure to represent it and the modernity of the architectural project of bullring that signed with the bullfighter Luis Miguel Dominguín and the architec Antonio Bonet i Castellana. Comparison of that new project of 1964 with the projects and renovations of other Spanish and American bullrings.

Keywords: Picasso; architecture; bullrings; engraving; ceramic.

La afición taurina de Picasso es bien conocida, está documentada a través de fotografías que constatan su presencia en el ruedo además de su producción artística dedicada al tema. Bergamín le llamó "matador de toros de la pintura", definición que encaja a la perfección con su entusiasmo por ambas cosas ${ }^{1}$. Los testimonios artísticos de esa afición son notables, como se demuestra desde sus primeras obras realizadas en Málaga y en La Coruña. El cuadro titulado El pequeño picador amarillo (1890) y el grabado titulado El zurdo (1899), centrados

${ }^{1}$ BERGAMÍN, José: Prólogo del catálogo de la exposición Picasso. Dibujos, gouaches, acuarelas. Barcelona, 1961. 
ambos en la figura del picador, expresan la afición que le fue inculcada por su padre, José Ruiz Blasco. Pudo verse la relación de Picasso con la tauromaquia en las exposiciones que tuvieron lugar entre los años 1993-1994 en las ciudades de París, Barcelona y Bayona. Bajo el título Picasso. Toros y Toreros, se reunieron cerca de doscientas obras realizadas entre 1890 y 1970, muestras de pintura, escultura, dibujos, acuarelas, grabados, litografía y cerámica². La extensión de las fechas que abarcaba la exposición demostró que prácticamente desde su infancia había estado vinculado a ese mundo. En esas obras puede rastrearse la idea que tenía el pintor sobre la figura ideal de una plaza de toros que va cambiando con el paso del tiempo, hasta decantarse por un edificio moderno y rompedor como se constata en el proyecto arquitectónico que firmó junto al torero Luis Miguel Dominguín y al arquitecto Antonio Bonet i Castellana ${ }^{3}$.

$\mathrm{Su}$ visión del ruedo comienza a fijarse desde los años finales del siglo XIX. Enfoques parciales de plazas de toros que más parecen sacados de fotografías que pintados del natural. En ellos podemos ver cosos circulares no identificables, cuya perspectiva nos muestra las primeras filas de los tendidos, como se aprecia en Corrida (La Coruña, 2 de septiembre de 1894) o en Corrida de toros (1896). Son pinturas que enlazan con la tradición pictórica del siglo XIX dedicada al tema que, sin duda, fueron punto de referencia para el joven pintor. A partir de 1900, la presencia de arquitecturas taurinas se intensificará en sus obras. En esa época, Picasso vivió en Barcelona, donde se acababa de inaugurar la plaza de toros de Las Arenas que desplazaría la antigua llamada El Torín, situada en la Barceloneta ${ }^{4}$. Algunas de las pinturas de esa época muestran vistas de plazas de toros como Toro tirado por la cola (1900), La Corrida (1900) o Corrida de toros (1901). En las tres aparece la perspectiva de unos tendidos y gradas bajo arcos que sirven de marco a distintas suertes de la lidia. Resulta difícil identificar realmente la plaza de toros, tal vez porque están pintadas de memoria y no del natural, como él mismo le afirmó a Jaime Sabartés ${ }^{5}$. Las tres vistas se diferencian de otra pintura de esa misma época titulada La Corrida (1900), en la que aparece la inscripción "Pozuelos", donde el referente arquitectónico ha cambiado por completo, sin que se pueda identificar la ubicación de esa inscripción partiendo de la propia

${ }^{2}$ Catálogo de la exposición Picasso. Toros y Toreros. París, 1993; Barcelona, 1993; y Bayona, 1994.

${ }^{3}$ PERALES PIQUERES, Rosa: "El proyecto de la plaza de toros de Picasso y su relación con la arquitectura de masas", Quintana, 13, 2014, pp. 267-281.

${ }^{4}$ GONZÁLEZ MORENO-NAVARRO, Antoni: "La desventurada historia de El Torín, la primera plaza de toros permanente de Barcelona”, Revista de Estudios Taurinos, 26, 2009, pp. 61-78.

5 SABARTÉS, Jaime: Picasso. Portraits et souvenirs. París, 1946, p. 201. 
biografía de Picasso ${ }^{6}$. En todas ellas, aparecen claramente delimitadas los contrastes entre las dos zonas de la plaza -sol y sombra- que se proyectan sobre el amarillo del ruedo.

Durante su etapa cubista, las referencias taurómacas en la obra picassiana son escasas, aunque no por ello dejó de asistir a corridas de toros tanto en España como en el sur de Francia, según puede comprobarse por la correspondencia del artista. Será a partir de 1917 cuando de nuevo tome el tema taurino fijado particularmente en la figura del caballo como víctima de la brutalidad del toro, puesto que en esa época aún salían al ruedo sin el caparazón protector que los defendía. Por esas fechas, eligió el tema taurino como referencia para diseñar los decorados y vestuario para el gran empresario de los Ballets Rusos, Serge Diaghi$\operatorname{lev}^{7}$. En uno de esos decorados, concretamente el que realizó en 1919 para el ballet Le tricorne con música de Falla, aparece una escena taurina que tiene como fondo la gradería de una plaza de toros donde unas majas presencian, sentadas en un palco, el arrastre de las mulillas. A pesar de la influencia goyesca, está presenta en ese decorado toda la pintura taurina decimonónica de temas similares. La tauromaquia seguirá presente en su producción, pero la presencia de arquitecturas taurinas no las va a retomar hasta años más tarde. Las cogidas mortales de los toreros Joselito y Manuel Granero fueron el desencadenante del conjunto de obras dedicadas a la muerte del torero. Pinturas cuyo carácter trágico rehúye de presentarnos apenas esbozos de perspectivas de la plaza para adentrarnos directamente en el meollo del drama.

En 1928, recibió el encargo por parte de su amigo Gustavo Gilli i Roig de ilustrar La Tauromaquia de José Delgado, Pepe Illo, con una introducción de Montherlant, quien acababa de publicar Les bestiaires, un relato de sus experiencias tauromáquicas en España, publicado en 1926. Existen siete aguafuertes de esta primera tentativa que se conocen con el nombre de Primera Tauromaquia, según la catalogación de la obra gráfica del artista que realizó Bernhard Geiser en $1933^{8}$. Llama la atención la falta de carácter ilustrativo de las suertes de la lidia que tienen estas estampas, muy condicionadas por las fuertes líneas del dibujo y por las reminiscencias clásicas de su pintura en esa época, que finalizaría en la década de los treinta con la irrupción del Minotauro. La fallida tentativa de esta ilustración se volvería a retomar en la década de los años cincuenta como veremos.

\footnotetext{
${ }^{6}$ OCAÑA, María Teresa: "1892-1900. Picasso novillero", en Picasso. Toros y Toreros. Barcelona, 1993, p. 99.

7 CARRETE PARRONDO, Juan: "Picasso y la Danza", en Picasso. La Danza (De Le Tricorne a Las Suites 347 y 156). Valencia, 2008; y CARRETE, Juan y MERA, Guadalupe: "Picasso-Parade-El sombrero de tres picos-Falla", en Picasso-Falla. Málaga, 2013.

${ }^{8}$ GEISER, Bernhard: Picasso, peintre-graveur. Catalogue ilustré de l'ouvrage gravé e lithographié, 1899-1931. Berna, 1933.
} 
El ruedo está presente de nuevo a partir de los años cuarenta como se aprecia en pinturas, litografías y cerámicas. La variedad de pinturas dedicadas al mundo taurino es encomiable, pero en ellas el protagonista fundamental será el toro como símbolo o como instrumento al servicio de una idea y, en menor medida, los protagonistas de la lidia ${ }^{9}$. No sucede lo mismo con los grabados y la cerámica, donde Picasso recrea las suertes de la corrida con una fijación absoluta por la figura del picador. Estas dos formas de expresión artística serán fundamentales para mostrarnos su idea sobre el ruedo, sus preferencias sobre la figura que debe tener y los elementos arquitectónicos que componen una plaza de toros. Unas veces se decantará por fijar una elipse, mientras que en otras primará la forma circular. De igual forma, nos presentará la imagen del ruedo desde perspectivas arquitectónicas muy forzadas, en las que a veces dominará la horizontalidad del ruedo elíptico, mientras que en otras la verticalidad es absoluta con el círculo como protagonista. A partir de 1950, le interesará más el estudio de las suertes de la lidia donde tienen cabida las vistas de la plaza, como se aprecia en muchas obras de esa época pintadas de forma esquemática y, a veces, desgarradora.

Mediada la década de los cuarenta, Picasso comenzó a vivir intermitentemente en el sur de Francia, donde frecuentó la relación de intelectuales que acudían a esa zona, presenciando juntos corridas de toros en los años posteriores a la Segunda Guerra Mundial. Michel Leiris, Jean Cocteau, Jean Dubuffet, el poeta Blaise Cendrars, André Masson o André Castel fueron compañía habitual del artista malagueño en las plazas francesas ${ }^{10}$. Años en los que Picasso abandonaría la forma implacable de representar la fiesta de toros que adoptó tras las sucesivas guerras -la española y la mundial- por un tipo de imagen más amable y centrada en los avatares de la lidia. De los años cuarenta son sus dibujos de las divisas de las ganaderías y su famosa cabeza de toro compuesta con un sillín y manillar de bicicleta, a los que seguirían sus series cerámicas y dibujos. Esa visión más benigna de la fiesta estuvo en consonancia con la propia evolución del toreo de ese momento, que se iba alejando de la lidia feroz de los años treinta para adentrarse en otro tipo de corrida con un toro más templado ${ }^{11}$.

El descubrimiento de la técnica ceramista fue relevante en este sentido a través de los dibujos que componen las obras de esa etapa de su vida. En 1946, decidió acercarse a la exposición anual de cerámica de Vallauris donde confluían alfareros del sur de Francia para exponer sus objetos, muchos de carácter popular, realizados con diferentes técnicas. Allí conoció a Suzanne y Georges Ramis, quienes le convencieron para permanecer en esta pequeña localidad, ante la

${ }^{9}$ CARMONA MATO, Eugenio: La metamorfosis de la fiesta. El mito taurino en la obra gráfica de Pablo Picasso. Sevilla, 1988, pp. 44-45.

${ }^{10}$ Sobre este tema ver MAÏLLIS, Annie: Picasso et Leiris dans l'arène. Les escrivains, les artistes et les toros (1937-1959). Pau, 2002.

${ }^{11}$ MARTÍNEZ NOVILLO, Álvaro: Le peintre et la tauromachie. París, 1988, p. 51. 
fascinación que le produjo experimentar con nuevos medios de producción artística. Suzanne Ramié era una reconocida ceramista que enseñó a Picasso las técnicas de trabajar el barro en el taller Madoura donde tenía sus hornos, lo que le suponía enfrentarse a nuevos materiales que transformarían durante ese periodo parte de su arte. Con el fin de permanecer en esa zona, compró y transformó una granja, Les Fournas, instalando su estudio en esta localidad entre 1947 y 1951, dedicándose fundamentalmente a la cerámica, a la escultura y a la pintura, aunque la práctica ceramista no la abandonaría nunca.

En esta localidad francesa, promovió levantar una plaza de toros portátil, donde se dieron corridas durante el verano de los años 1954 a $1960^{12}$. Las fiestas de toros que se celebraron comportaron festejos con toros embolados o juegos taurinos, aparte de las novilladas en las que participaban toreros de renombre, alguno de ellos amigo de Picasso. Los festejos se hacían con novillos que al final del espectáculo regresaban al corral. Solo se mataron los toros una vez, con motivo del festival que se celebró para agasajar a Picasso por su ochenta cumpleaños. En este caso se trajeron los toros de España y toreó Luis Miguel Dominguín junto a Domingo Ortega. A pesar de la prohibición explícita de matar toros en esa plaza, Picasso determinó que así se hiciera, a pesar del peligro de cárcel que podía acarrearle la decisión, pero quería ver la corrida "como es en España"13. Los festejos eran anunciados en carteles impresos a partir de unos linograbados que el propio Picasso realizaba, algunos de gran potencia expresiva ${ }^{14}$.

Una parte importante de la producción cerámica de ese periodo está dedicada a la reproducción de escenas taurinas desarrolladas en fuentes, platos y baldosas. La superficie sobre la que iba a estampar sus ilustraciones -fuentes ovaladas o platos-, independientemente de la escultura, le sirvió de marco para evocar un coso taurino, bien de forma redonda o con la referencia oval de los anfiteatros romanos a los que tan habitualmente estaba acostumbrado en esa zona del sur de Francia. Destaca la serie indivisible de ocho platos, tirada a cincuenta números de ocho platos cada uno, cuyas medidas eran $42 \mathrm{~cm}$ de diámetro. Denominada "Corrida Rosa" por utilizar para su fabricación pasta de loza rosa con motivos en relieve que iban resaltados con óxido negro, representaban ocho escenas de corridas de toros. Los dibujos y matrices de esta serie permitieron hacer una segunda versión, con la única diferencia que los motivos en relieve en lugar de estar subrayados con trazos negros aparecen sobre grandes manchas polícromas, por lo que se las denominó "Corrida de las Manchas"15. Aparte de estas series realizó platos

12 RAMIÉ, Georges: Cerámica de Picasso. Barcelona, 1974, p. 261. Las fechas de estas series se hallan entre 1949 y 1959.

13 ABELLA, Carlos: Luis Miguel Dominguín. A corazón abierto. Madrid, 2016, p. 278.

${ }^{14}$ LEAL, Brigitte; OCAÑA, María Teresa y BERNADAC, Marie-Laure: "19451972. Sol y Sombra”, en Picasso. Toros y Toreros. Barcelona, 1993, pp. 237-251.

15 RAMIÉ, Georges: Cerámica de Picasso, op. cit., p. 170. 
redondos sueltos representando diversas suertes y baldosas, muchas de las cuales se conservan en el Musée d'Art Moderne de Céret.

Entre sus primeras producciones destacan una serie de fuentes ovaladas -con títulos como Corrida, Pase de capa, El banderillero, Las banderillas, El picador, etc.- fechadas entre $1947-1949^{16}$. En ellas muestra el movimiento y la simplificación de las figuras que deben ajustarse y constreñirse al marco del recipiente. Servirán de patrón a las escenas taurinas para dibujar la cerámica y, posteriormente, para la ilustración de libros. Centradas en las suertes de la corrida, Picasso no se determina aún por ofrecernos la arquitectura de la plaza ni su forma. Algunos dibujos muestran una influencia del Matisse de los cuadros dedicados a Ícaro, cuya figura evoca Picasso en las figuras de toreros y picadores, aunque tratados con mayor vibración y agilidad. En 1949, aparecerá en un plato cuadrado redondeado

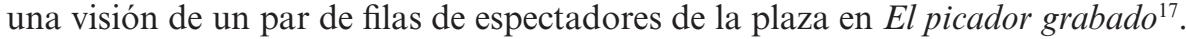
En cuanto a la representación picassiana de la lidia, presenta ciertos desajustes con respecto a la época: el picador haciendo la suerte de frente y adelantando la vara según los cánones clásicos, opuesto a otras ventajas de la época o la representación del caballo sin peto que estaba prohibido ${ }^{18}$.

A partir de 1953, la serie de platos muestran vistas de plazas de toros, alguna de ellas con picadores y toreros en primer término, como el denominado Picador grabado y pintado, cuyo tamaño $(42 \mathrm{~cm})$ le permitía jugar con una audaz perspectiva hasta entonces imposible. A partir de ese año, las vistas arquitectónicas del ruedo se hacen presentes para fuentes ovaladas y platos redondos. En el primer caso, resulta evidente evocar los modelos de anfiteatros romanos a los que tan acostumbrado estaba por su presencia constante en las corridas de Arles y de Nîmes. De hecho, en alguna de ellas son reconocibles estos cosos. La sutileza en el tratamiento de las figuras contrasta con pinturas de temática taurina de esa época en los que la violencia y fuerza de la escena o del toro acapara la atención del espectador. En estos dibujos, la corrida se plasma en todas sus suertes, alcanzando gran sutileza y espontaneidad: paseíllo, lances de capa, suerte de varas, picadores, banderilleros, faenas de muleta, estocadas y arrastre. La fugacidad de los lances se representa captando lo efímero del momento. Los rebordes de las fuentes ovaladas acogen una multitud de espectadores que se apiñan en las gradas, sugeridos a través de una multiplicidad de puntos.

Alterna la forma arquitectónica del ruedo, elíptica o circular, en la serie de platos pequeños redondos (17,3 cm de diámetro), fechados en 1953, que conservan también en el Musée d'Art Moderne de Ceret. Uno de ellos, titulado Corrida, nos muestra la parte exterior de un coso redondo que evoca la plaza de toros de

${ }^{16}$ Estas fuentes miden $31 \times 37,5 \mathrm{~cm}$.

17 Medidas: $24 \times 24 \mathrm{~cm}$.

${ }^{18}$ LUQUE TERUEL, Andrés: "Picasso: algunas consideraciones sobre la lidia", en Fiesta de toros y sociedad. Sevilla, 2003, pp. 719-739. 
la Puerta de Alcalá de Madrid, derribada en 1874, pero muy conocida a través de grabados $^{19}$. En otros dibujos de esta serie, a pesar de tratarse de un plato redondo pequeño, enmarca la escena taurina dentro de una elipse, teniendo como referencia, de nuevo, los anfiteatros romanos. De las veintinueve piezas de que consta esta serie, solo seis mantienen el coso taurino de forma circular. Resulta relevante el plano que ofrece con respecto a la escena, tratándose de una vista desde las gradas superiores de la plaza y no desde la barrera, lugar al que normalmente concurría cuando presenciaba las corridas. Es evidente que ese ángulo le permitía dar una visión completa del ruedo, de la posición del torero frente al toro y, en definitiva, de los terrenos del toro. La perspectiva arquitectónica se acerca y se aleja de la arena donde los protagonistas de las lidia destacan en sus distintas suertes.

En 1959, cuando de nuevo aborde el tema taurino en la cerámica con la serie titulada Corrida, realizada con algo de relieve y decoración negra sobre pasta de loza común, la redondez del coso prima sobre cualquier otra figura. Volvió a repetir esa misma serie con la diferencia de realizarla a base de decoración polícroma sobre pasta de loza blanca, reproduciendo el coso circular y la presencia de los espectadores tras las barreras. Algunas de estas cerámicas muestran un modelo que, posteriormente, tratará de reproducir cuando firme, junto a Luis Miguel Dominguín y Antonio Bonet, el proyecto para una plaza de toros, antes citado. Notables en este sentido son las que exhiben una plaza de toros cubierta con óculo en la parte central por donde se cuelan los rayos solares, en contraste con otras vistas de la plaza a cielo descubierto. Como comentaremos más adelante, en el proyecto de la plaza de toros picassiana estaba previsto cubrirla con una cubierta movible, evocando quizá los velarium que cubría el anfiteatro Flavio de Roma y que, posteriormente, se ha visto en algunas de las plazas modernas que se han construido.

Picasso recreó también la arquitectura taurina en las veintiséis estampas taurinas que hizo para ilustrar La Tauromaquia o Arte de Torear de José Delgado, alias Pepe Illo, en 1957. De esta forma, retomó el proyecto que le encargó Gustavo Gilli i Roig en 1928 a través de la figura de su hijo Gustavo Gilli i Esteve. Las veintiséis aguatintas, tiradas en el taller Lacourière-Frélaut de París, representan diferentes momentos de la lidia plasmadas con rigurosa exactitud. Su facilidad para el dibujo y la técnica que empleó le permitieron captar los movimientos y fuerza de cada una de las fases de la fiesta, mostradas con figuras silueteadas a través de la superposición de manchas negras de distinta densidad. Las figuras están tratadas como si fuesen siluetas de un teatrillo de sombras con una focalización de las escenas en primer plano y a ras de tierra que captan a la perfección la fugacidad y espontaneidad de la corrida. Uno de ellos, titulado $A$ los toros,

${ }^{19}$ LÓPEZ IZQUIERDO, Francisco: "Plaza de Toros de la Puerta de Alcalá, 17491874”, Anales de Madrid, Madrid, 1983; y MARTÍNEZ NOVILLO, Álvaro: La plaza de toros de la Puerta de la Alcalá y su época. Madrid, 1992, pp. 87-134. 
muestra claramente la fachada del anfiteatro de Arles, donde solía acudir a presenciar las corridas. La fachada del mismo anfiteatro también puede verse en otro dibujo fechado en 1959 titulado Corrida a Arles ${ }^{20}$.

La serie presenta todas las suertes del toreo del momento, algunas de ellas desaparecidas en la actualidad, como las que exhiben el salto de la garrocha o el célebre don Tancredo. La técnica empleada fue el aguatinta, lo que le permitió trabajar con grandes manchas monocromas que contrastaban con el blanco del papel. Las estilizadas figuras de picadores, toreros y mozos, contrastan con la potente figura del toro, protagonista indiscutible de la serie. El dinamismo de las figuras hace que parezcan danzantes dentro del ruedo carentes de la tensión emocional de las corridas de los primeros decenios del siglo. En este sentido, la diferencia con la Tauromaquia de Goya es total, ya que el pintor aragonés personaliza a muchos de los protagonistas de su serie. Y mientras que Picasso integra a los espectadores en algunas de las suertes, Goya prefiere aislar a los protagonistas de la fiesta en el ruedo. Movimiento, algarabía y bullicio son las características que podemos encontrar en esta serie, muy relacionada en su forma y estética con lo experimentado en la cerámica. De hecho, muchas de las estampas parecen inspirarse directamente en los dibujos de platos y fuentes realizados con anterioridad. En ellos aparece, en la mayoría de los casos, un ruedo ovalado, salvo en el que se aprecia la fachada del anfiteatro de Arles.

Una diferencia notable si comparamos la producción cerámica de tema taurino y esta serie de estampas es el punto de vista desde donde apreciamos las distintas suertes del toro dentro del ruedo. En el caso que nos ocupa, Picasso nos ofrece una visión de la lidia desde la barrera o desde tendidos muy bajos, incorporando en alguna de ellas a los protagonistas directos de la corrida, que aparecen de espaldas al espectador. Así lo vemos en la titulada Echando el perro al toro, en la que la semblanza del picador aparece de espaldas en primer término junto a otros toreros y público o la titulada Citando al toro a banderillas sentado en una silla, en la que la presencia de las figuras de dos toreros acompañados de un picador, todos de espaldas, acaparan la atención junto a la suerte del ruedo ${ }^{21}$.

Parte de la producción pictórica de Picasso centrada en el mundo de toros quedó patentizada en el libro publicado en 1961 titulado Toros y Toreros que realizó junto a su gran amigo Luis Miguel Dominguín, quién le escribió el prólogo. El libro recogía dibujos y aguadas de Picasso, tomados directamente en la plaza de toros, de picadores, caballos derribados, movimientos de capas de los toreros, retratos de personajes de los tendidos y una insólita visión del paseíllo, realizados entre el 13 de junio de 1957 y el 4 de diciembre de 1959. Esta obra ampliaba el libro de Jean Clarence Lambert, publicado en 1960, dedicado exclusivamente al

\footnotetext{
${ }^{20}$ LAMBERT, Jean Clarence: Picasso. Dessins de Tauromachie, 1917-1960. París, 1960

${ }^{21}$ Catálogo de la exposición Goya-Picasso. La Tauromaquia. Zaragoza, 1981.
} 
análisis de los dibujos taurómacos del pintor ${ }^{22}$. Picasso había conocido al torero Luis Miguel Dominguín en 1958 a través de su amigo Jean Cocteau. El pintor, que vivía en esos momentos en La Californie, villa situada en las colinas de Cannes, compró en esa misma fecha el espléndido château de Vauvenargues, cerca de la localidad francesa de Aix-en Provence, donde instaló su taller y reposan hoy sus restos ${ }^{23}$. Picasso vio por primera vez el château precisamente tras asistir a una corrida de toros con Cocteau y lo compró una semana más tarde de esa primera e impactante impresión. Casualmente la propiedad se encuentra situada a la espalda del Mont Sainte-Victoire tan célebremente pintado por otro pintor francés al que Picasso admiraba, Paul Cézanne.

La historia de la amistad Picasso-Dominguín, que permaneció durante muchos años, acrecentó aún más su afición a los toros, siendo múltiples las imágenes en las que aparece con el torero, bien en la plaza o en otros ámbitos. De la recíproca afición a los toros y de la colaboración entre ambos artistas, que fue muy intensa en esos años en los intercambiaron ideas y opiniones, surgió el proyecto de levantar una plaza de toros. De hecho, la proposición partió de Dominguín, quien le planteó hacerla para la Feria del Campo que se celebraba cada año en la Casa de Campo de Madrid. La pretensión de Dominguín fue que Picasso la diseñara y que llevase su nombre. El proyecto debería incluir un espacio en los pisos inferiores para guardar y exhibir permanentemente las pinturas del artista dedicadas al tema taurino. El entusiasmo de Picasso ante la idea de Dominguín fue de tal dimensión que llegó a diseñar un aparato de relojería, que a la hora del comienzo de la corrida debía proyectar su perfil en la arena, según la dirección del sol $^{24}$. El lugar escogido, la Casa de Campo, era el más idóneo, habida cuenta que dentro del recinto se encontraba la Venta del Batán, inaugurada en 1950 por iniciativa del ayuntamiento de Madrid con el apoyo del entonces empresario de la plaza de toros de las Ventas, Livinio Stuick. En el cercado de estas instalaciones, compuesta por corrales y viviendas para los mayorales de las ganaderías, se exhibían los toros que iban a ser lidiados en la Feria de San Isidro. Fue el entonces alcalde de Madrid, José María Finat, conde de Mayalde, hombre afín al régimen y amigo personal de Franco y de Serrano Suñer, quien se opuso al proyecto, al considerar que la Casa de Campo "era patrimonio del pueblo madrileño"25.

Pero la idea de construir una plaza de toros no le era ajena a Picasso. De hecho, como se ha expuesto, fue el promotor de levantar una plaza portátil en Vallauris para celebrar festejos, donde él mismo tentó vaquillas algunas veces. Por

${ }^{22}$ LAMBERT, J. C.: Dessins de Tautomachie, op. cit.

${ }^{23}$ ELY, Bruno: Château de Vauvenargues. París, 2009; SOBIK, Helge: Picasso's home. Dusseldorf, 2009; y PAIR, Alain: Pablo Picasso a Vauverangues. Le grand atelier de la Sainte Victoire. París, 2009.

${ }^{24}$ ALELLA, C.: Luis Miguel Dominguín..., op. cit., p. 272.

${ }^{25}$ Ibidem. 
otro lado, Dominguín estaba familiarizado con las plazas de toros en general y con las de tienta en particular, pues en la finca que tenía su padre, Domingo González "Dominguín", "La Companza", en el término de Quismondo (Toledo), se construyó una plaza para herraderos, tentaderos y faenas del campo, así como para torear él y sus hijos. Se trata de un pequeño coso circular, cuyo palco principal había proyectado Fernando Chueca Goitia, configurándolo como un cuerpo cúbico de dos plantas rematado en forma piramidal. El segundo cuerpo estaba abierto con unas arquerías de tres tramos, siendo el central mayor y con menor peralte $^{26}$. El proyecto sigue la tradición arquitectónica de los edificios de esta índole, de la que finalmente se apartarían Dominguín y Picasso cuando idearon su futuro proyecto común de plaza de toros.

La necesidad de contar con un arquitecto para el proyecto hizo que se fijaran en Antonio Bonet i Castellana, a quien Picasso había conocido mientras que ambos trabajaban en el Pabellón Español de Nueva York en 1937 y a quien seguía tratando, puesto que el arquitecto pasaba parte del verano en el sur de Francia. Bonet, catalán de nacimiento, comienza su vida profesional trabajando con Josep Lluís Sert y Torres Clavé. Tras el estallido de la guerra civil se marchó a París, donde colaboró con Le Corbusier, pasando posteriormente a América, donde desarrolló gran parte de su carrera en Argentina y Uruguay ${ }^{27}$. Arquitecto, urbanista y diseñador, se puede considerar como uno de los grandes impulsores de la vanguardia artística y arquitectónica de los años treinta, destacando particularmente las obras emprendidas entre los años 1959-1964, con estudios abiertos en Buenos Aires y Barcelona, donde se instaló definitivamente en 1964, aunque el proyecto y construcción de la casa Gomis (La Ricarda) en Barcelona se fecha entre 1953$1963^{28}$. Bonet no tenía experiencia en edificios de este tipo, pues en el ejercicio de su profesión había hecho proyectos arquitectónicos y urbanísticos que abarcaban viviendas comunitarias y particulares, además de ordenaciones urbanas de distinta índole. La experiencia más cercana la constituía el proyecto y construcción del Canódromo de Barcelona, realizado entre 1961-1963, que le sirvió de referencia en el proyecto taurino a la hora de utilizar materiales como el aluminio para los cerramientos o los paneles de cristales móviles. El éxito de ese proyecto, que recibió el premio FAD de arquitectura en 1963, pudo constituir la causa de la elección de Picasso y Dominguín para que participase con ellos en el diseño de la

${ }^{26}$ CHUECA GOITIA, Fernando: "Plaza de tienta «La Companza»", Revista Nacional de Arquitectura, 93-94, 1949, pp. 445-447.

27 ÁLVAREZ, Fernando et al.: Antonio Bonet Castellana (1913-1989). Barcelona, 1996; y ÁLVAREZ, Fernando y ROIG, Jordi: Antonio Bonet Castellana. Barcelona, 1999.

28 ARNALDOS MONTANER, Almudena: "Antonio Bonet Castellana, Le Corbusier y la bóveda catalana: forma y orden”, Dearq, 14, 2014, pp. 122-135. 
plaza de toros, además de la intencionalidad de ambos de hacer una plaza dentro de las corrientes arquitectónicas más modernas ${ }^{29}$.

La modernidad del proyecto de Bonet revela la capacidad de ambos artistas -Picasso y Dominguín- para escoger un arquitecto capaz de interpretar sus novedosas ideas con respecto a las formas de una plaza de toros. Muchos de los planos y alzados de la plaza, si bien están firmados por el arquitecto catalán, las firmas que destacan son las del torero y las del pintor, ambas más unidas y gruesas, mientras que las del arquitecto se muestra en un extremo y con letra más pequeña. Además de las anotaciones del propio Picasso para la decoración cerámica que pensaba diseñarle. La forma del ruedo es circular, desechando otro tipo de figura a pesar de la familiaridad de la forma elíptica a la que estaba acostumbrado el pintor y que tan sabiamente había plasmado en cerámica y dibujos.

Dos elementos novedosos definirán el proyecto: la propuesta de situar parte del graderío por debajo del nivel del suelo y de hacerle una cubierta. Con respecto a la primera idea, se proyectó una parte del edificio por debajo del nivel de tierra con el fin de darle mayor cabida al edificio. No era una novedad desde el punto de vista arquitectónico, pues ya se había experimentado algo semejante en tierras mexicanas. Bonet debía conocer el proyecto de la plaza de toros Monumental de México, la de mayor aforo del mundo, diseñada por el ingeniero Modesto C. Rolland en 1945, cuya parte del graderío se situaba por debajo del nivel de la calle ${ }^{30}$. Tampoco era ninguna novedad en España, aunque en este caso nunca se llegó a realizar. La idea de situar los tendidos por debajo del nivel del suelo para ganar aforo se había planteado ya en la plaza de toros de Sevilla en las reformas que se pensaron llevar a cabo en los comienzos del siglo XX al tratar de reducir el anillo y contar con un mayor número de barreras ${ }^{31}$.

La otra novedad era la cubierta, consistente en una bóveda invertida que cubría la plaza en su totalidad, reforzada por la sujeción de pivotes de hierro, lo que permitía su uso nocturno al dotarla de suficiente luz. Esos pivotes se fortalecerían con unos tirantes exteriores que ampliaban el espacio circundante del edificio. Además, para regular su luz interna, incluía unas placas verticales de vidrio

${ }^{29}$ PERALES PIQUERES, R.: "El proyecto de la plaza de toros de Picasso...", op. cit., pp. 267-281.

${ }^{30}$ ROLLAND, Jorge M.: "El ingeniero Modesto C. Rolland, pionero del uso del prefabricado de cemento armado en México", Construcción y tecnología en concreto, febrero 2015, pp. 36-41, http://www.revistacyt.com.mx/pdf/febrero2015/historico.pdf (Consultado el 22-11-2016); y JUSTIN CASTRO, J.: "Modesto C. Rolland and the developmentof Baja California", Journal of the Southwest, vol. 58, n² 2, 2016, pp. 261-291.

${ }^{31}$ HALCÓN, Fátima: La plaza de toros de la Real Maestranza de Caballería de Sevilla. Madrid, 1990, pp. 161-177; y HALCÓN, Fátima: "Aníbal González y la reforma de la plaza de toros de Sevilla”, Revista de Estudios Taurinos, 8, 1998, pp. 137-156. 
que permitían manipular la luz interior durante la lidia ${ }^{32}$. El edificio constaría con tres partes diferenciadas, una superior de hierro y vidrio, el espacio medio con la estructura del graderío que llegaba por debajo del nivel del suelo y, por último, el coso. El acceso se haría mediante rampas, y las taquillas estarían situadas en la parte inferior. Los toriles y demás accesorias se localizaban fuera del edificio principal. La idea remite a los dibujos cerámicos de Picasso, donde se aprecia un coso taurino cubierto con un óculo central, incluso en las imágenes en las el coso aparece de forma elíptica.

A pesar de que en las conversaciones iniciales del proyecto entre Dominguín y Picasso se pretendía hacer un museo con toda la obra taurina del pintor que incluía pinturas, dibujos y cerámica, finalmente se optó por incorporar la cerámica picassiana al proyecto arquitectónico. Así, en la parte superior de la bóveda invertida se colocarían relieves "a la manera clásica", entendiendo por ello que podrían retomar la idea del Minotauro como base de esa decoración. De esta forma el contorno superior de la plaza exhibiría esos relieves, visibles incluso desde el exterior. La decoración cerámica contemplaba también homenajear a los toreros más famosos de la historia mediante la reproducción de sus figuras, realizadas en colores neutros sobre un fondo rojo oscuro ${ }^{33}$. No hay que olvidar que Picasso había estado inmerso en los talleres de cerámicos de Vallauris hasta poco antes del proyecto de la plaza y de esos talleres salieron gran parte de su producción ceramista dedicada a tema taurino.

La plaza finalmente no se llegó a construir, no solo por la negativa del alcalde de Madrid, sino también porque la edificación del coso iba a requerir la presencia permanente de Picasso en la capital de España, hecho que en el año 1964 no parecía posible por la propia negativa de Franco, a pesar de que le había comentado a Dominguín que si el pintor pasaba la frontera con él, nada le iba a ocurrir $^{34}$. Con ello, la arquitectura taurina española se quedó sin lo que podía haber sido un edificio innovador, singular y único dentro de esa tipología que, además se hubiese convertido en un museo permanente al incorporar la cerámica de Picasso.

La novedad del planteamiento picassiano distaba mucho de otros edificios similares que se habían construido o se estaban remodelando por esa época que se mantuvieron firmes en las formas clásicas de la arquitectura taurina. La más similar en cuanto a incorporación cerámica es La Monumental de Barcelona realizada en 1913 por Manuel Joaquín Raspall i Mallol y reformada en 1914-1915

32 PERALES PIQUERES, R.: "El proyecto de la plaza de toros de Picasso...”, op. cit., p. 276.

${ }_{33}$ Ibidem, p. 278.

${ }^{34}$ ALELLA, C.: Luis Miguel Dominguín..., op. cit., p. 271. Dominguín comentó que Franco, en una ocasión delante suya, llamó a Camilo Alonso Vega, entonces ministro de la Gobernación, para decirle que cualquier persona que entrase en España sin documentación y viniese acompañada del torero podía entrar por cualquier frontera española. 
por Ignasi Mas i Morel1 ${ }^{35}$. Barcelona, que contaba con una larga tradición taurina, fue la primera plaza de toros del mundo en número de corridas, hasta llegar a programar el treinta por ciento de los espectáculos taurinos del mundo entre 1954-1965 ${ }^{36}$. Desde el punto de vista arquitectónico y estructural la plaza no presenta grandes novedades. El ruedo de planta circular con sus graderíos correspondientes, ordenándose alrededor del mismo los edificios anexos -cuadras, chiqueros, etc.-- El interés de la plaza se centra en su parte externa con ocho torres de planta cuadrada para las escaleras, cuatro de las cuales se rematan en cúpulas de influencia oriental recubiertas de cerámica azul y blanca. Igualmente, el adorno de cerámica con esos mismos colores se integra en los muros que se sitúan entre estas torres. El uso de la cerámica como adorno arquitectónico tenía una gran tradición en Cataluña desde la época gaudiana y sentaría las bases de otros modelos que se hicieron por toda la geografía española. En este sentido, el uso de materiales como el ladrillo y la cerámica, unido a su propia estética arabizante, se entiende más desde esa perspectiva modernista catalana que desde la intención recuperadora de "mudejarismo" presente en otras muchas plazas de toros españolas. No hay que olvidar que el arquitecto que participa en el proyecto era de origen catalán.

Otra plaza de toros que utiliza la cerámica como adorno arquitectónico, en este caso de nuevo en su fachada externa, es la plaza de toros de las Ventas de Madrid. La primera plaza de toros que tuvo Madrid la mandó construir Fernando VI, situándose junto a la Puerta de Alcalá, siendo el autor de su proyecto Juan Bautista Sachetti, quien lo firmó en $1749^{37}$. La plaza permaneció hasta 1870 que fue derribada, debido al ensanche de esa zona de la ciudad. Ante la gran afición a las corridas se decidió levantar otra plaza en 1874 en la Fuente del Berro, donde se encuentra hoy el Palacio de Deportes. Conocida como plaza de toros de Goya, fue diseñada por los arquitectos Emilio Rodríguez Ayuso y Lorenzo Álvarez Capra, siendo de las primeras que presentaba decoración neomudéjar en su fachada. Al tener solo cabida para 15.000 espectadores pronto se quedó pequeña ante el auge que adquirió el toreo en España entre 1910-1920, por lo que se contempló la

${ }^{35}$ Sobre las plazas de toros de Barcelona ver BASSEGODA NONEL, Joan: "L'afer de la plaça de toros Las Arenas de Barcelona", Butlleti de la Real Academia Catalana de Belles Arts de San Jordi, 3, 1989, pp. 60-71.

${ }^{36}$ BOIX, Salvador: "La Barcelona taurina. De los días de gloria al futuro incierto", Revista de Estudios Taurinos, 26, 2009, pp. 79-93.

37 HERNÁNDEZ, R.: Historia de las plazas de toros de Madrid, 1874-1934. Madrid, 1955; AA.VV.: Las Ventas: libro del cincuentenario de la plaza. Madrid, 1981; BONET CORREA, Antonio: "Arquitectura de las plazas de toros de Madrid", en Las Ventas: cincuenta años de corrida. Madrid, 1981; LÓPEZ IZQUIERDO, Francisco: Plazas de toros de Madrid. Madrid, 1985; y LÓPEZ IZQUIERDO, Francisco: "Las plazas de toros en el siglo XIX”, en Cursos de verano Aranjuez. Aranjuez, 2002. 
posibilidad de construir una nueva. La iniciativa para construirla la llevó a cabo uno de los toreros más famosos del momento: José Gómez Ortega, Joselito el Gallo o Gallito, quien manifestó la conveniencia de hacer una plaza de mayor tamaño que pudiera abaratar las entradas a todos los públicos. Su amistad con el arquitecto José Espeliús posibilitó llevar a cabo el proyecto.

La plaza se construyó en unos terrenos que la familia Jardón, ganaderos, cedieron a la Diputación Provincial en las llamadas Ventas del Espíritu Santo, con la condición de explotarla durante cincuenta años. Las obras comenzaron en 1922, finalizándose en 1929, aunque no fue inaugurada oficialmente hasta 1934. De planta circular, exenta, de tres cuerpos en el interior y cuatro en el exterior, construida con muros exteriores de fábrica de ladrillo visto, ornamentada con cerámica vidriada y estilo neomudéjar, como era la moda de la época. El arquitecto Manuel Muñoz Monasterio, que llevó la dirección de las obras a partir de 1928, fue el encargado de diseñar la decoración de cerámica vidriada de colores, predominantemente blanco y azul, donde figuran los escudos de todas las provincias españolas y otros motivos ornamentales.

La modernidad de la cubierta en el proyecto de la plaza de toros que proyecta Bonet con Picasso y Dominguín no se aplicó en edificios de esa tipología hasta años más tarde. Así se constata en plaza de toros de Zaragoza, conocida como la Misericordia, construida en el siglo XVIII siguiendo el modelo de la plaza de toros de Aranjuez ${ }^{38}$. Se reformó prácticamente en su totalidad en 1917 siguiendo el proyecto de los arquitectos Miguel Ángel Navarro Pérez y Manuel Martínez de Ubago Lizarraga para evitar los costosos gastos de arreglos de carpintería ${ }^{39}$. En esta reforma se transformó toda la parte externa con el aspecto más moderno, sustituyendo lo que debía ser un muro compacto con pequeñas ventanas. Habría que esperar a 1989 para incluir en un proyecto de renovación la incorporación de una cubierta móvil de teflón que presenta un óculo central con el fin de darle al edificio una finalidad multifuncional y poderse utilizar de noche y en días de lluvia.

Otro modelo que conocemos de cubierta es el de la plaza de toros de Pamplona, que tras el incendio y destrucción de la plaza de toros primitiva en 1921, se construyó otra por iniciativa de la Casa de la Misericordia, inaugurándose en $1922^{40}$. La proyectó el arquitecto Francisco de Urcola en estilo neorrenacentista,

${ }^{38}$ HERRANZ ESTODUTO, Alfonso: Los orígenes de la plaza de toros de Zaragoza, 1764-1818. Zaragoza, 2008; y VÁZQUEZ ASTORGA, Mónica: "El cartel taurino zaragozano del siglo XIX”, Artigrama, 18, 2003, pp. 573-600.

${ }^{39}$ MARTÍNEZ MOLINA, Javier y RINCÓN GARCÍA, Wifredo: "La plaza de toros de Zaragoza desde su construcción en 1764-1765 hasta su reforma en 1916-1918", en El coso de la Misericordia de Zaragoza, 1764-2014. Zaragoza, 2014, pp. 61-113; y YESTE NAVARRO, Isabel: "La plaza, de la obra de Navarro y Martínez Ubago (1916-1918) a la actualidad”, en El coso de la Misericordia de Zaragoza..., op. cit., pp. 113-149.

${ }^{40}$ CAMPOS JESÚS, L.: Pamplona y sus plazas de toros. Pamplona, 1982. 
fachada exterior con dos galerías (la baja cubierta y descubierta la alta). Parecida a la Monumental de Sevilla, fue de las primeras realizadas en hormigón armado encargándose de su construcción Martinicorena Mendizábal y Co. Se ha vuelto a reformar varias veces, siendo la más interesante la proyectada en 1967 por Rafael Moneo, que le añadió el graderío alto y lo remató con una ligera cubierta metálica.

La interesante propuesta de Bonet hubiera significado un revulsivo dentro de la arquitectura taurina. En esa fecha (1964) las plazas de toros de las grandes capitales españolas, incluida la de Vista Alegre de Bilbao, que se había finalizado dos años antes siguiendo el proyecto del arquitecto Luis de Gana y Hoyos, estaban todas finalizadas. La arquitectura externa del coso bilbaíno denota el modernismo imperante en la arquitectura del momento. Otras plazas de toros estaban siendo remodeladas en la década de los sesenta, como la de Valencia, que en los años 1967-1968 se llevó a cabo una reforma que afectó a la reducción del ruedo para aumentar en tres filas los tendidos además de sustituir todas las gradas que aún le quedaban de madera, pero sin afectar a su estructura externa ${ }^{41}$. O la de Mérida, donde igualmente se amplió el aforo y se suprimió el tejadillo que cubría las andanadas, pero sin afectar a la fachada ${ }^{42}$.

Lamentablemente, el proyecto quedó solo en tentativa. La forma de utilizar los materiales, el cuidado de los más mínimos detalles, la ausencia total de referencias historicistas tan de moda en edificios similares, la tendencia a la verticalidad en la parte alta del edificio, los tirantes externos y la modernidad arquitectónica que presenta lo hubiesen convertido en un ejemplo único y en el último referente moderno de plaza de toros, puesto que a partir de esa época las plazas de toros existentes se reformaron o readaptaron sin existir un proyecto similar ni en España ni en América.

Fecha de recepción: 18 de diciembre de 2016

Fecha de aceptación: 9 de enero de 2017

${ }^{41}$ AA.VV.: Plazas de Toros de España. Sevilla, 1992, p. 264.

${ }^{42}$ NÚÑEZ CHAMORRO, Manuel: Las tres plazas de toros de Mérida. Badajoz, 1982, pp. 21-25. 


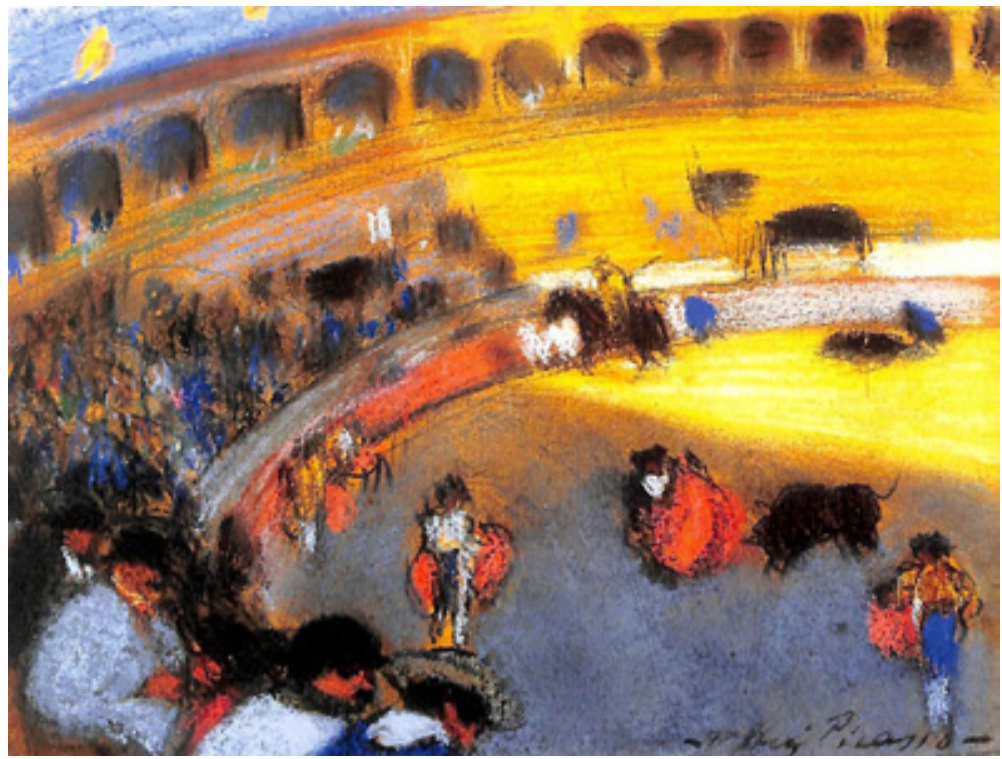

Figura 1. Pablo Picasso, La corrida, Barcelona, 1900, óleo sobre lienzo, colección privada, Barcelona.

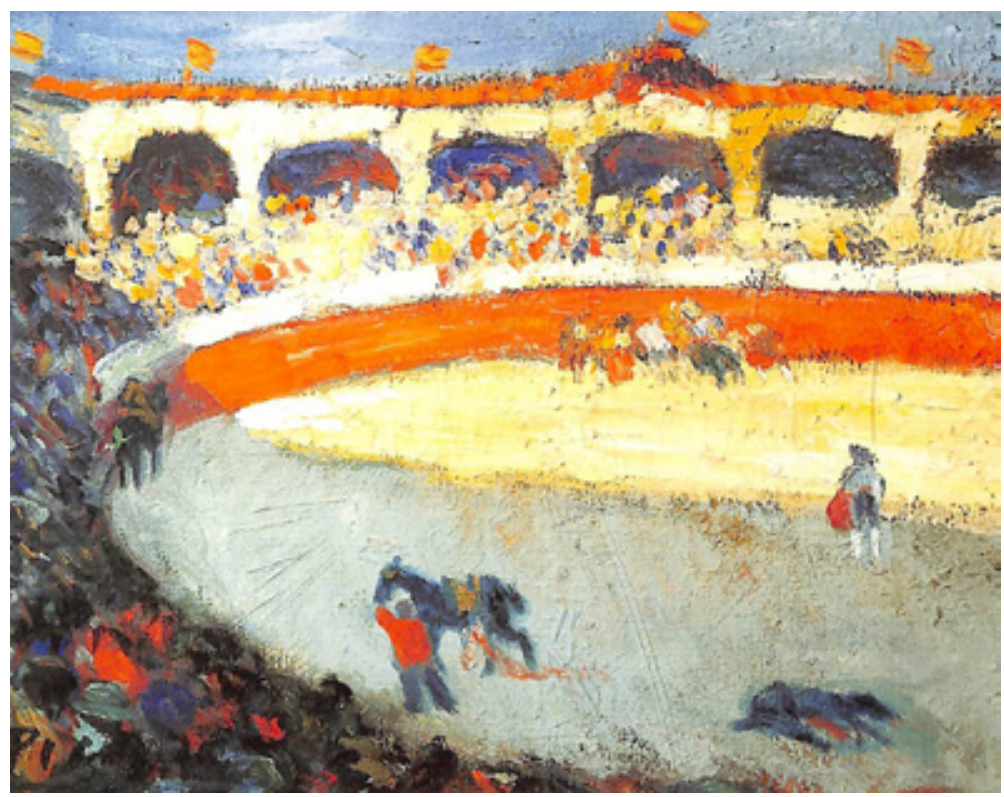

Figura 2. Pablo Picasso, Corrida de toros, 1901, óleo sobre lienzo, colección privada, Nueva York. 


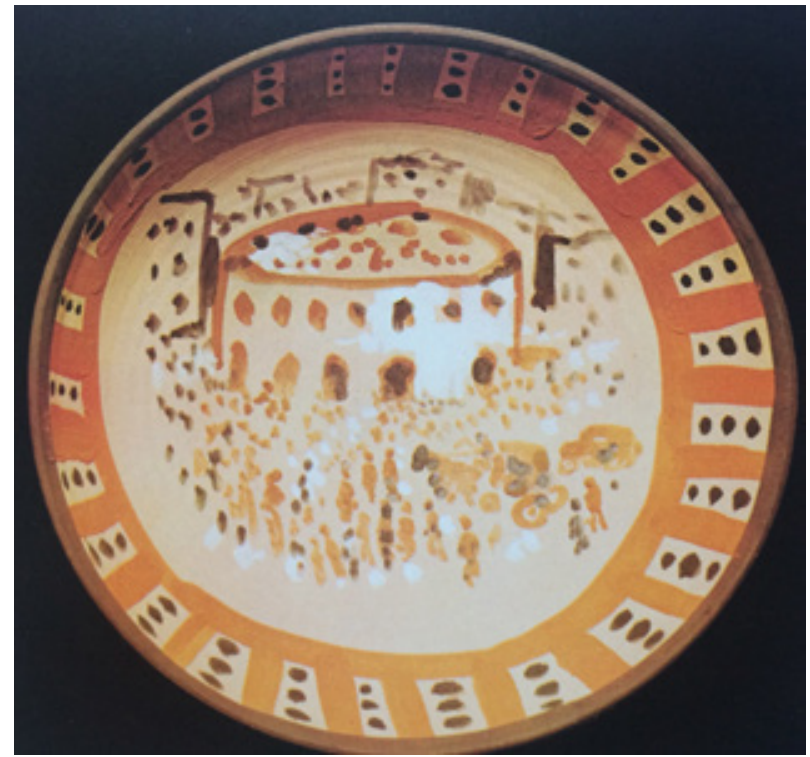

Figura 3. Pablo Picasso, Corrida, 1953, plato redondo de cerámica, Musée d'Art Moderne, Céret.

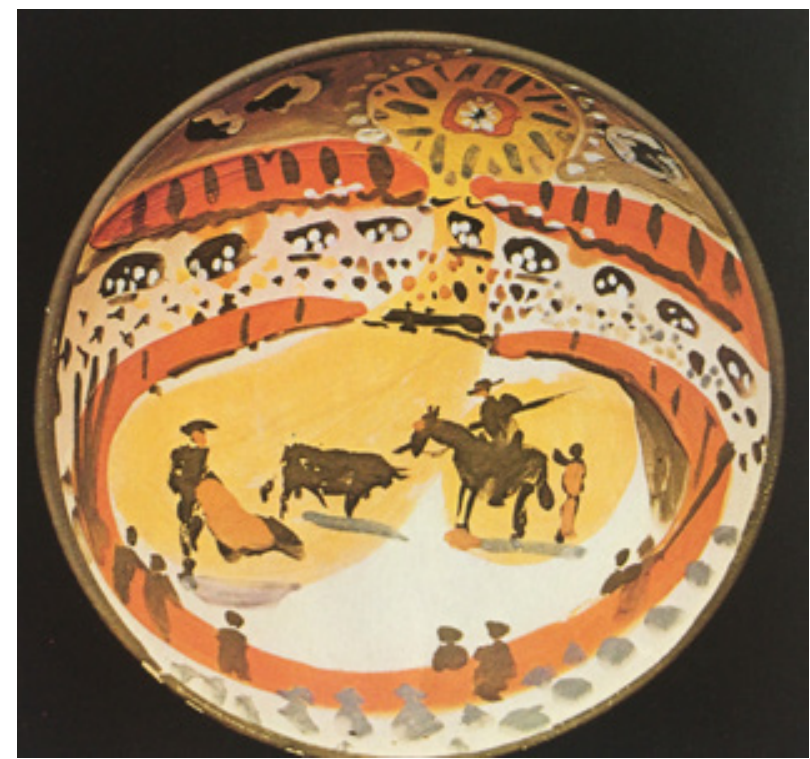

Figura 4. Pablo Picasso, Corrida, 1953, plato redondo de cerámica, Musée d'Art Moderne, Céret. 


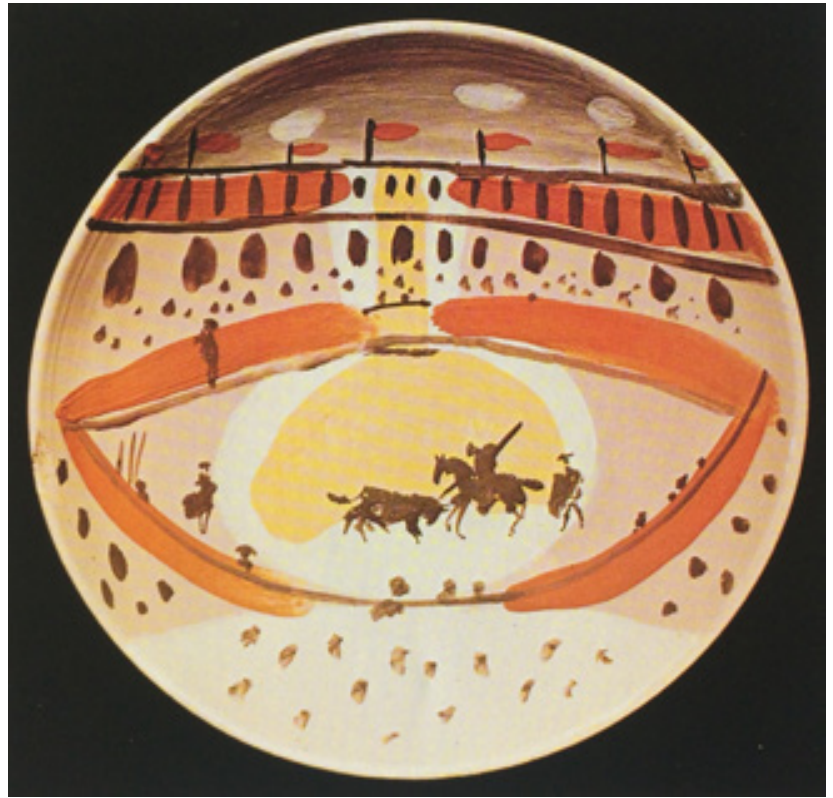

Figura 5. Pablo Picasso, Corrida, 1953, plato redondo de cerámica, Musée d'Art Moderne, Céret.

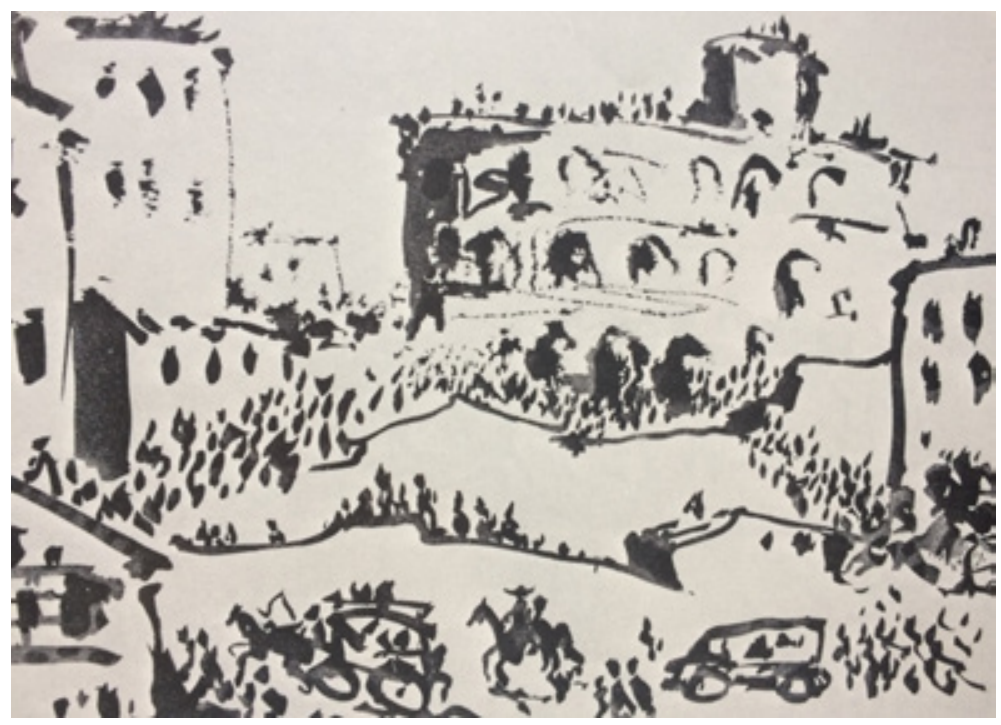

Figura 6. Pablo Picasso, A los toros, 1957, aguatinta sobre cobre, Tauromaquia de Pepe Illo. 


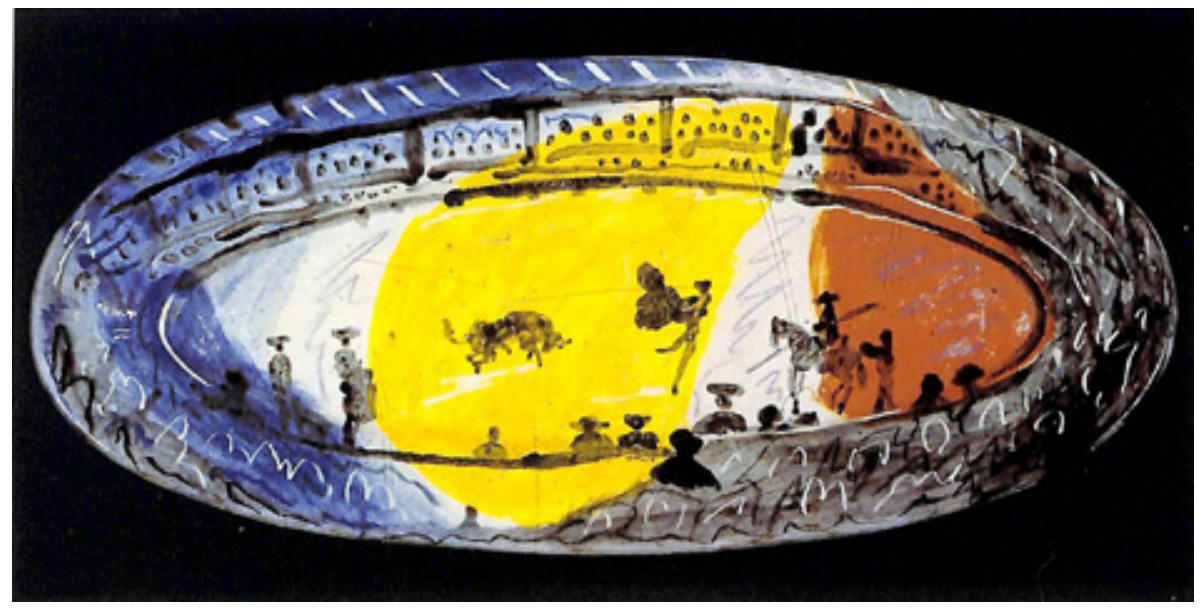

Figura 7. Pablo Picasso, Corrida, Vallauris, 1957, fuente ovalada de cerámica, Musée d'Art Moderne, Céret.

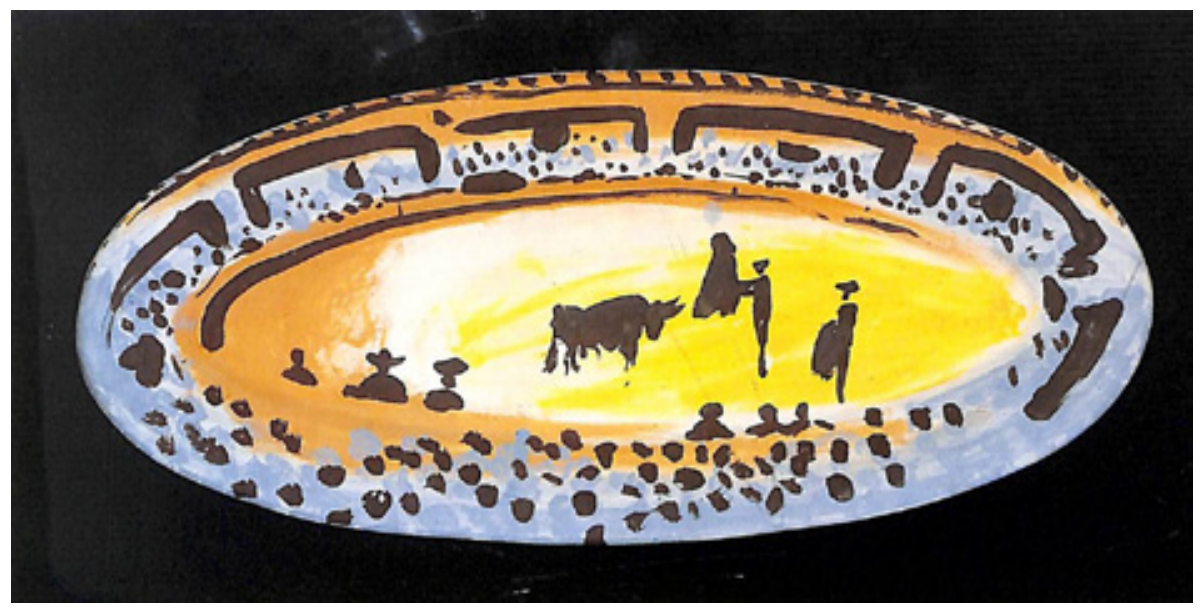

Figura 8. Pablo Picasso, Corrida, Vallauris, 1957, fuente ovalada de cerámica, Musée d'Art Moderne, Céret. 


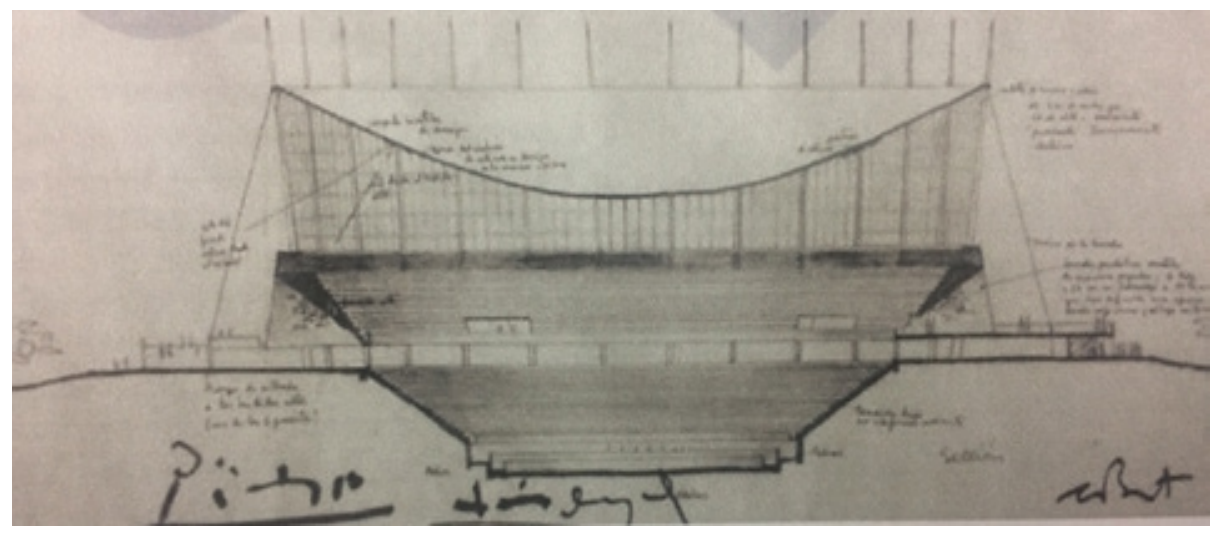

Figura 9. Antonio Bonet, Pablo Picasso y Luis Miguel Dominguín, Proyecto de plaza de toros, 1964. Procedencia:

http://www.usc.es/revistas/index.php/quintana/article/viewFile/1642/3082. 